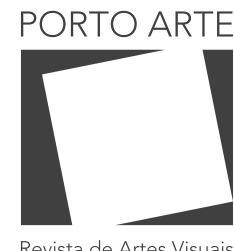

v. 25 n. 44 Jul/dez 2020 e-ISSN: 2179-8001

\section{Palavras originárias e pensamentos visíveis: ambivalência,} imagem, criação

Original words and visible thoughts:ambivalence, image, creation

\section{Diego Rezende}

ORCID: 0000-0002-4652-8439

Universidade Federal do Rio de Janeiro

\section{Resumo}

Investigação que tem como objetivo analisar e aprimorar os processos de criação em torno das excitações intelectuais provocadas pela "ambivalência". Em um primeiro momento, examinaremos o desenvolvimento do conceito de "ambivalência" nos textos psicanalíticos de Sigmund Freud. Para isso, abordaremos seus trabalhos sobre a noção de "inconsciente" e sobre o significado de "palavras originárias". Em um segundo momento, analisaremos imagens criadas por René Magritte no intuito de explorarmos a "ambivalência" presente em seus "pensamentos visíveis". E, em um terceiro e último momento, articulando os tópicos anteriores, esboçaremos a possibilidade de delimitarmos uma "poética visual da ambivalência".

Palavras-chave

Ambivalência. Criação. Imagem. Inconsciente. Poética.

\section{Abstract}

Research that seeks to analyze and improve the creative processes around the intellectual excitations caused by "ambivalence". At first, we will examine the development of the concept of "ambivalence" in Sigmund Freud's psychoanalytic texts. For this, we will approach your work on the notion of "unconscious" and on the meaning of "original words". In a second step, we will analyze images created by René Magritte in order to explore the "ambivalence" present in his "visible thoughts". And, in a third and last moment, articulating the previous topiCS, we will outline the possibility of delimiting a "visual poetics of ambivalence".

Keywords

Ambivalence. Creation. Image. Unconscious. Poetic. 


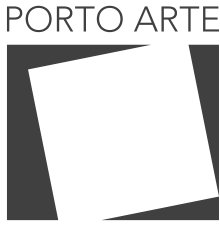

Revista de Artes Visuais

$\vee 25 n .44$

$\mathrm{Jul} / \mathrm{dez} 2020$ e-ISSN: 2179-8001

\section{Introdução}

Inicialmente, torna-se preciso abordar o sentido do título apresentado em nosso trabalho. 0 que chamamos aqui de palavras originárias são conceitos fundamentais que surgiram nos processos de comunicação de povos originários. E o que chamamos de pensamentos visíveis são tentativas intelectuais de se trabalhar visualmente derivações inóspitas da nossa mente. A partir de tais concepções, propomos o diálogo entre as investigações linguísticas de Sigmund Freud (1856-1939) e as investigações plásticas de René Magritte (1898-1967). Freud estudou o sentido antitético da antiga língua egípcia e o sentido bífido da palavra polinésia tabu. Magritte criou imagens que buscavam dar forma visual a suas elucubrações. Ambos pensadores possuem um ponto em comum: trabalharam a fundo o conceito de ambivalência.

Esse é, justamente, o objetivo do nosso estudo: aprofundarmos o conceito de ambivalência no intuito de analisarmos e aprimorarmos os processos de criação em torno de suas excitações intelectuais. Para isso, destrincharemos o trabalho em três tópicos, seguindo o subtítulo: ambivalência, imagem, criação. No primeiro tópico, buscaremos elucidar os estudos freudianos sobre o inconsciente e sobre palavras originárias - fontes de derivações ambivalentes. No segundo tópico, abordaremos as formações visuais de determinadas obras plásticas de Magritte, considerando especialmente as derivações ambivalentes presentes na reversibilidade entre as dimensões do interior e do exterior em suas pinturas. E, no terceiro e último tópico, articulando os dois tópicos anteriores, esboçaremos a possibilidade de delimitarmos uma poética visual da ambivalência que se compõe como ferramenta conceitual para estudos posteriores.

\section{Ambivalência: inconsciente e palavras originárias}

Comecemos pelos fundamentos do conceito de inconsciente estabelecidos por Sigmund Freud nas primeiras décadas do século XX. É importante salientar que tal conceito é tratado de modo vasto na psicanálise e em outros campos do conhecimento, porém, abordaremos o inconsciente segundo os trabalhos freudianos no intuito de elucidarmos um arcabouço teórico que nos ofereça sustentação para nos situarmos em torno de um processo de criação, de uma poética, que tenha a ambivalência como válvula propulsora. De imediato, torna-se preciso incitar a abertura conceitual para um ponto analítico que promove o que pretendemos arquitetar enquanto ambivalência: a valência simultânea de opostos em um mesmo lugar. Lugares abstratos como uma palavra ou como uma imagem serão usados por nós como ferramentas experimentais de exploração do inconsciente. Mas o que é isso que estamos chamando de inconsciente?

$\mathrm{Na}$ elaboração de um breve histórico sobre o conceito, Luciana Chaui-Berlinck descreve que Ernst Platner (1744-1818) foi o primeiro a usar, em alemão, o termo inconsciente (Unbewusste). Logo, a inovação de Freud não está no fato de falar sobre o inconsciente, mas sim - como ele mesmo escreveu já no final da vida - de levar o inconsciente a sério e de dar um conteúdo novo ao conceito, buscando conhecer suas características e suas leis de funcionamento (CHAUI-BERLINCK, 2014, p. 27). 


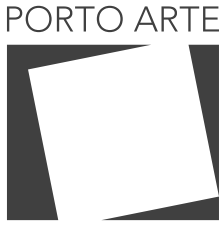

Revista de Artes Visuais

v $25 n \cdot 44$

$\mathrm{Jul} / \mathrm{dez} 2020$ e-ISSN: 2179-8001

Nas palavras de Freud: "A diferenciação do psíquico em consciente e inconsciente é a premissa básica da psicanálise e o que a ela permite compreender e inscrever na ciência os processos patológicos da vida psíquica" (FREUD, 2011, p. 15). Nesse sentido, além de destrinchar a fundo os elementos da neurose, Freud estuda os fenômenos da hipnose e do sonho e se dá conta que uma psicologia que tinha a consciência como núcleo de atenção não resolvia os problemas levantados por esses fenômenos. Segundo ele:

\begin{abstract}
"Estar consciente" é, em primeiro lugar, uma expressão puramente descritiva, que invoca a percepção imediata e segura. A experiência nos mostra, em seguida, que um elemento psíquico por exemplo, uma ideia - normalmente não é consciente de forma duradoura. É típico, isto sim, que o estado de consciência passe com rapidez; uma ideia agora consciente não o é mais no instante seguinte (FREUD, 2011, p. 16).
\end{abstract}

Porém, tal ideia que agora não é mais consciente pode voltar a ser consciente em determinadas condições possíveis de se produzirem com atenção e energia necessárias. Nesse intervalo, como pontua Freud, podemos dizer que essa ideia era latente, capaz de consciência, ou podemos também descrevê-la como inconsciente: "Possuímos dois tipos de inconsciente: o que é latente, mas capaz de consciência, e o reprimido, que em si e sem dificuldades não é capaz de consciência" (FREUD, 2011, p. 17). 0 que é latente, apenas descritivamente inconsciente, foi chamado por Freud de Pré-consciente. Já o reprimido, dinamicamente inconsciente, foi denominado Inconsciente. Temos aqui a formulação da primeira tópica ${ }^{1}$ freudiana: Inconsciente (Ics), Pré-consciente (Pcs) e Consciente (Cs) - elaborada junto aos primeiros trabalhos psicanalíticos, estrutura o aparelho psíquico de acordo com lugares abstratos: sistemas dinâmicos e econômicos de funcionamento.

No avanço da obra freudiana, uma segunda tópica surgiu em seus trabalhos. Sendo assim, o aparelho freudiano foi elaborado segundo duas tópicas. Para além da primeira, descrita acima, a segunda tópica, admitida a partir da década de 1920, apresentou um aparelho fendido em Id, Eu e Supereu - segundo a tradução de Paulo César de Souza que usamos aqui. Em linhas gerais, o Id - o isso, tratando-se de algo do qual falamos apontando para ele - é o reservatório de libido, da energia psíquica sexual. 0 Eu - ou Ego, segundo algumas traduções - é o núcleo mediador, local da razão e do bom senso. E o Supereu - ou Superego - é a consciência moral, a instância da ordem e da proibição. Torna-se relevante destacar que essas divisões são tidas como transições, ou seja, um elemento presente em um determinado lugar é passível de deslocamento fronteiriço. Além disso, torna-se também importante enfatizar que uma tópica não ex-

\footnotetext{
1- Tópos, em grego, significa lugar. Segundo Freud: "Provisoriamente, nossa topologia psíquica nada tem a ver com a anatomia; ela se refere a regiões do aparelho psíquico, onde quer que se situem no corpo, e não a locais anatômicos" (FREUD, 2010b, p. 112).
} 


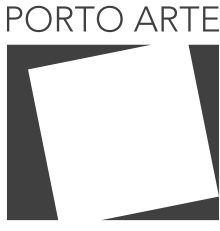

Revista de Artes Visuais

v. 25 n. 44

$\mathrm{Jul} / \mathrm{dez} 2020$ e-ISSN: 2179-8001

clui a outra, a segunda é criada de acordo com a insuficiência da primeira no trabalho prático (FREUD, 2011, p. 20), mas não é abandonada por Freud no seguimento da sua escrita. Para fins didáticos, em nosso estudo em torno do inconsciente, utilizaremos apenas o instrumental criado pela primeira tópica freudiana.

Retomando a primeira tópica, o conceito de Ics é, portanto, adquirido a partir da noção de repressão: "O reprimido é, para nós, o protótipo do que é inconsciente" (FREUD, 2011, p. 17). No trabalho analítico, a força que provoca e mantém a repressão é sentida como resistência. E, para transpor essa resistência, é necessário certo esforço:

\begin{abstract}
Ao tentar fazê-lo em nós mesmos, temos a nítida sensação de uma defesa que deve ser superada, e, ao provocar isso num paciente, obtemos inequívocos sinais do que chamamos de resistência contra isso. Desse modo vemos que o pensamento inconsciente é excluído da consciência por forças vivas, que se opõem à sua acolhida (FREUD, 2010a, p. 264).
\end{abstract}

Diante disso, o Ics é uma fase primordial e inevitável dos processos que fundamentam nossa atividade psíquica: "todo ato psíquico começa inconsciente e pode permanecer assim ou desenvolver-se rumo à consciência, segundo encontre resistência ou não" (FREUD, 2010a, p. 264). Mas o que move o Ics e todo o aparelho psíquico? A resposta está no único conceito que, de fato, é originário do campo psicanalítico (MAGNO, 2015, p. 167) e que Freud, escrevendo em língua alemã, deu o nome de Trieb².

Retornando e dizendo de outro modo, Freud descreve os processos de censura presentes na primeira tópica:

Enunciemos agora, como resultado da psicanálise, que um ato psíquico passa geralmente por duas fases em relação ao seu estado, entre as quais se coloca uma espécie de exame (censura). Na primeira fase ele é inconsciente e pertence ao sistema Ics; se no exame ele é rejeitado pela censura, não consegue passar para a segunda fase; então ele é "reprimido" e tem que permanecer inconsciente. Saindo-se bem no exame, porém, ele entra na segunda fase e participa do segundo sistema, a que denominamos sistema Cs. Mas essa participação não chega a determinar inequivocamente a sua relação com a consciência. Ela ainda não é consciente, mas capaz de consciência (na expressão de J. Breuer [Josef Breuer (1842-1925)]), isto é, pode então, dadas certas condições, tornar-se objeto da cons-

\footnotetext{
2- Trieb é "o motor do funcionamento do aparelho psíquico, é uma pressão ou força que afeta o organismo desde dentro e o impele a realizar ações que buscam provocar uma descarga de excitação, ou seja, provocar a satisfação" (CHAUI-BERLINCK, 2014, p. 55). A tradução do termo Trieb por instinto e do termo Triebregung - usada como sinônimo - por impulso instintual é largamente utilizada no trabalho de Paulo César de Souza, estando presente na tradução da obra freudiana que citamos em nossa investigação. Porém, Trieb também pode ser traduzido para a língua portuguesa como Pulsão ou, sendo ainda mais consonante à língua, como Tesão - definido por MD Magno.
} 


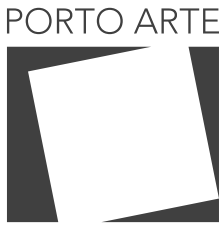

Revista de Artes Visuais

25 n 44

$\mathrm{Jul} / \mathrm{dez} 2020$ e-ISSN: 2179-8001

ciência sem maior resistência. Tendo em vista essa capacidade de consciência, chamamos o sistema Cs também de "pré-consciente" (FREUD, 2010b, pp. 109-110).

Portanto, dentro da primeira tópica, podemos obter dois sistemas de fluxo: o Ics e o Pcs/Cs - na qual o Pcs partilha as propriedades do sistema Cs. Mas continuamos com duas passagens que se constituem como censuras: a passagem do Ics para o Pcs - onde há uma censura rigorosa - e a passagem do Pcs para o Cs.

\begin{abstract}
$\mathrm{Na}$ fronteira do Pcs, o Ics é rechaçado pela censura, e derivados dele podem contornar essa censura, organizar-se superiormente, crescer no Pcs até atingir certa intensidade no investimento, mas depois de a haver ultrapassado, ao procurar se impor à consciência, são reconhecidos como derivados do Ics e novamente reprimidos na nova fronteira de censura entre Pcs e Cs. Assim, a primeira censura funciona para o Ics mesmo; a última, para os derivados Ics dele (FREUD, 2010b, p. 135).
\end{abstract}

O que seriam esses derivados? Freud esclarece que derivados do Ics se tornam conscientes como formações substitutas e sintomas, frequentemente, após consideráveis distorções em relação ao inconsciente (FREUD, 2010b, p. 135). Ou seja, para atravessar a censura, nosso Ics disfarça seus conteúdos, faz concessões e acordos. Logo, o Ics não se apresenta diretamente, pois resultaria em uma enorme resistência por parte do Cs e seria barrado pela censura. Além disso, se algo inconsciente se apresentasse como consciente, deixaria de ser inconsciente. Portanto, o que é inconsciente não pode ser observado nem localizado de modo direto, mas apenas por meio de derivados, substitutos disfarçados ou sintomas, que podem ser investigados nos sonhos, nos chistes, nos lapsos de linguagem, nos equívocos de memória, no esquecimento de nomes, na negação e nos sintomas neuróticos - dando apenas alguns exemplos explorados por Freud. Tais pressupostos nos coloca diante da pedra angular em que se assenta o edifício da psicanálise: o recalque ${ }^{3}$. E, analogamente, com a constituição do retorno do recalcado. Em outras palavras, entrelaçando os nomes já descritos, o que Freud chama de recalque se faz justamente nos mecanismos de censura e de defesa e o que chama de retorno do recalcado se elabora através de derivados e substitutos. Eis a formatação fundamental da dimensão inconsciente na primeira tópica do aparelho freudiano.

Diante disso, o inconsciente "não é o lugar das trevas, da falta de razão e do ilógico; ele tem sua própria 'lógica', que não é a mesma do consciente" (CHAUI-BERLINCK,

\footnotetext{
3- "Esse termo é usado muitas vezes por Freud com um sentido que o aproxima de 'defesa', como um dos métodos de defesa utilizados pelo eu de cada indivíduo. É empregado para designar o destino das representações eliminadas da consciência e que constituem o núcleo de um grupo psíquico separado. Esse grupo psíquico separado nada mais é do que o Inconsciente e, por isso, diz-se que o recalque institui o Inconsciente" (CHAUI-BERLINCK, 2014, p. 44).
} 


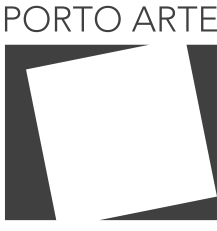

Revista de Artes Visuais

v. 25 n. 44

$\mathrm{Jul} / \mathrm{dez} 2020$ e-ISSN: 2179-8001

2014, p. 42). Indo mais fundo no conceito, o Ics possui outras características próprias e não habituais quando tomamos o regime da consciência como referência. São elas: a ausência de contradição, o processo psíquico primário ${ }^{4}$, a substituição da realidade externa pela realidade psíquica ${ }^{5}$ e atemporalidade ${ }^{6}$.

Ou seja, no Ics, não há contradição nem negação, os opostos se indiferenciam e ambos valem. Além disso, há um processo matriz que se move pela busca incessantemente de satisfação. Por fim, os processos do Ics não são cronologicamente organizados, sendo assim, não há a noção de tempo tão imposta à consciência e tudo se faz de modo atemporal: o primitivo e o presente estão, portanto, em um mesmo lugar. Diante desses pressupostos em torno do conceito de inconsciente na psicanálise, prossigamos destrinchando o trabalho freudiano e investigando tais características próprias do conceito.

O sonho foi uma das matérias-primas freudianas utilizadas para o nascimento da psicanálise. No sonho, há a formação visual de algo derivado do inconsciente, ou seja, a criação de imagens que tem como referência os domínios do inconsciente. Em um trecho presente em A interpretação dos sonhos, de 1900 - primeira obra distinguida como psicanalítica -, Freud assinalou essa característica marcante que podemos colocar em analogia com uma das propriedades fundamentais do inconsciente: a ausência de contradição.

\begin{abstract}
Altamente notável é o comportamento do sonho em relação à categoria da oposição e da contradição. Essa categoria é simplesmente negligenciada; o "não" parece não existir para o sonho. Com especial predileção, as oposições são reunidas ou figuradas numa unidade. O sonho também toma a liberdade de figurar um elemento qualquer pela sua antítese de desejo, de modo que de início não sabemos se um elemento que admite um oposto está contido positiva ou negativamente nos pensamento oníricos (FREUD, 2016, p. 341).
\end{abstract}

Nesse trecho, podemos enfatizar duas formas possíveis de ambivalência: quando os opostos são reunidos numa unidade e quando há a apresentação de um elemento qualquer pelo oposto desejado. Nos dois casos, um elemento transporta as propriedades de elementos opostos, mesmo que indiretamente. Essa dinâmica presente no trabalho do sonho reforça a ausência de contradição enquanto propriedade do inconsciente.

\footnotetext{
4- "Primário porque vem primeiro no desenvolvimento psíquico. É preciso que o aparelho se desenvolva até conseguir um funcionamento secundário; este é o funcionamento característico do sistema Pré-Consciente/Consciente" (CHAUI-BERLINCK, 2014, p. 60).

5- "Os processos do Ics tampouco levam em consideração a realidade. São sujeitos ao princípio do prazer: seu destino depende apenas de sua intensidade e de cumprirem ou não as exigências da regulação prazer-desprazer" (FREUD, 2010b, p. 128) 


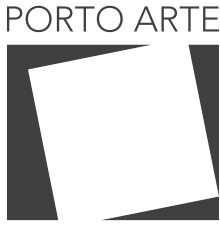

Revista de Artes Visuais

$\vee 25 n .44$ $\mathrm{Jul} / \mathrm{dez} 2020$ e-ISSN: 2179-8001

Porém, como Freud mesmo admitiu no ensaio Sobre o sentido antitético das palavras primitivas, de 1910 - publicado dez anos depois de A interpretação dos sonhos -, ele só chegou mesmo à compreensão da peculiar tendência do trabalho do sonho, que nos interessa aqui, por meio da leitura casual de um trabalho de Karl Abel (1837-1906) sobre a língua egípcia ${ }^{7}$. Segundo Freud, a leitura desse trabalho trouxe a espantosa informação de que a tendência do trabalho do sonho mencionada acima coincide com uma peculiaridade das línguas mais antigas que conhecemos (FREUD, 2013, p. 304). Nas palavras de Abel:

Na língua egípcia, esta singular relíquia de um mundo primitivo, há um número considerável de palavras com dois sentidos, em que um é o exato oposto do outro. Imaginemos - se tão evidente absurdo pode ser imaginado - que a palavra "forte", em alemão, signifique tanto "forte" como "fraco"; que em Berlim o termo "luz" seja empregado tanto para designar "luz" como "escuridão"; que um cidadão de Munique chame a cerveja de "cerveja", mas um outro use a mesma palavra quando se refere à água, e teremos a espantosa prática que os antigos egípcios costumavam seguir em sua linguagem (ABEL apud FREUD, 2013, p. 304).

O espanto de Freud e de Abel diante de tais constatações é intensificado pelo conhecimento que ambos detinham da cultura egípcia. Ou seja, o aparente contraste presente entre a formação da língua egípcia e seu desenvolvimento civilizatório. Em outra passagem, Abel complementa:

De todas as excentricidades do léxico egípcio, talvez a mais extraordinária tenha sido possuir, além de palavras que juntavam significações opostas, outras palavras em que dois vocábulos de significado oposto eram reunidos numa composição que tinha o significado de um dos dois membros constituintes. Portanto, nessa língua extraordinária existem não apenas palavras que designam tanto "forte" como "fraco", ou tanto "mandar" como "obedecer"; há também compostos como "velhojovem", “longeperto", "ligarseparar", "foradentro" [...], que, embora combinem extremos opostos, significam, a primeira, apenas "jovem", a segunda, apenas "perto", a terceira, apenas "ligar", e a quarta, apenas "dentro". [...] Ou seja, nessas palavras compostas juntaram-se intencionalmente contradições conceituais, não a fim de criar um terceiro conceito, como no chinês, mas apenas para exprimir, através da composição, o significado de um de seus membros contraditórios, que sozinho significaria o mesmo (ABEL apud FREUD, 2013, p. 306). 


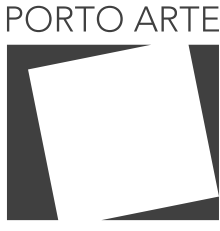

Revista de Artes Visuais

De acordo com Abel, podemos observar esse fenômeno do duplo sentido antitético nas mais antigas raízes da linguagem humana. No entanto, tal fenômeno acabou desaparecendo na evolução posterior dos vocabulários:

Os conceitos a que só se podia chegar de forma antitética tornaram-se, ao longo do tempo, suficientemente familiares ao espírito humano para possibilitar uma existência autônoma a cada uma das suas duas partes, e assim proporcionar um representante fonético distinto para cada uma delas (ABEL apud FREUD, 2013, p. 308).

Seguindo o exemplo de Freud: na escrita hieroglífica, a palavra ken - fortefraco - divide-se em ken - forte - e kan - fraco. Nossa insistência em citações referentes à linguagem de um Egito primevo se justifica pelo teor enriquecedor evidenciado na mesma para a orientação do nosso trabalho. Diante disso, retomemos a pergunta: como admitir a procedência de toda uma linguagem formada pela união de extremos opostos? Abel nos explica:

\footnotetext{
Assim, desde que todo conceito é irmão gêmeo de seu oposto, como poderia ele ser primeiramente pensado, como poderia ser comunicado a outras pessoas que buscavam pensá-lo, se não medido pelo seu oposto? [...] Como não se podia conceber a noção de força senão em contraposição a fraqueza, a palavra que denotava "forte" continha, ao mesmo tempo, a lembrança de "fraco", através da qual chegou a existir. Essa palavra, na verdade, não significava nem "forte" nem "fraco", mas a relação entre os dois e a diferença entre os dois, que criou ambos igualmente [...] 0 ser humano não pôde adquirir seus mais velhos e mais simples conceitos senão em oposição a seus opostos, e apenas gradualmente aprendeu a distinguir os dois lados da antítese e a pensar em um sem medi-lo conscientemente pelo outro (ABEL apud FREUD, 2013, pp. 306-307).
}

Sendo assim, originalmente, muitos conceitos elementares são dúbios, sendo formados pela força ambivalente existente entre sentidos opostos. Antes de poderem ser pensados diferenciadamente e tomados conscientemente no vocabulário, um conceito que abarca elementos opostos atravessa um momento no qual ainda vibra de acordo com derivações inconscientes originárias enquanto busca tomar escopo e realidade na língua onde se insere. Como exemplificado por Freud em seu ensaio, para além da língua egípcia, outras línguas também possuem palavras que se formaram de modo similar. Um exemplo significativo é a palavra inglesa without. Para dizer sem, usamos, em inglês, without, ou seja, comsem. With, que atualmente pode ser traduzido como com, significava originalmente tanto com como sem (FREUD, 2013, p. 310). 


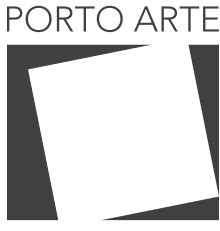

Revista de Artes Visuais

v. 25 ก. 44

$\mathrm{Jul} / \mathrm{dez} 2020$ e-ISSN: 2179-8001

Não é o caso aqui de irmos mais adiante na análise filológica de palavras primitivas, o que nos interessa é constatar o processo originário ambivalente presente na formação de conceitos fundamentais. Após um longo processo cultural de conversação da língua, as palavras se decompõem em diferenciações mais precisas em relação a suas qualidades opostas, porém, o campo de trabalho da nossa investigação está na raiz desse processo, na fonte de formatação da linguagem que, primariamente, é determinada pelo inconsciente. Dando continuidade e instituindo as bases do nosso lugar de observação, abordaremos outro conceito primitivo analisado por Freud: o tabu.

Tabu é uma palavra polinésia ${ }^{8}$ cujo significado se divide em duas direções opostas. Por um lado, quer dizer santo, consagrado. Por outro, significa impuro, perigoso, proibido. 0 contrário de tabu, em polinésio, é a palavra noa, que nos apresenta a noção de algo habitual e acessível. Logo, o tabu está ligado à dimensão de algo reservado que se exprime em proibições e restrições (FREUD, 2012, p. 42).

Baseando-se nos estudos de Wilhelm Wundt (1832-1920) ${ }^{9}$, Freud descreve o tabu como o mais antigo código de leis não escritas da humanidade, sendo mais antigo que os deuses e remontando a épocas anteriores a qualquer religião. Portanto, o tabu não procede do mandamento de uma divindade e de proibições morais (FREUD, 2012, pp. 42-43), mas, ao contrário, são as proibições morais e as tradições obedecidas por nós que se fundamentam nesse tabu primitivo.

Sobre o duplo sentido da palavra, Wundt explica que, nos primórdios do tabu, justamente por ser anterior a qualquer religiosidade, ainda não havia uma divisão entre sagrado e impuro (FREUD, 2012, p. 51). Sendo assim, os âmbitos do sagrado e do impuro coincidiam na origem da palavra tabu e só depois se diferenciaram no vocabulário. Nas palavras de Freud:

Nossa abordagem nos leva a concluir, sem dificuldade, que desde o princípio a palavra "tabu" tem esse duplo sentido, que ela serve para indicar uma determinada ambivalência e tudo o que se originou no terreno dessa ambivalência. "Tabu" é uma palavra ambivalente em si mesma, e acreditamos, a posteriori, que o sentido comprovado do termo já permite supor o que se obteve como resultado de ampla pesquisa, que as proibições do tabu devem ser vistas como produto de uma ambivalência emocional. 0 estudo dos mais antigos idiomas nos ensina que houve muitas palavras assim, que abrangiam opostos, que em certo sentido - embora não exatamente o mesmo - eram ambivalentes como a palavra "tabu". Pequenas mudanças fonéticas da palavra primitiva de significado antitético serviram, depois, para conferir expressão verbal diferenciada aos dois opostos ali reunidos (FREUD, 2012, p. 111).

\footnotetext{
B- Polinésia é o nome dado a um conjunto de ilhas ao sul do oceano Pacífico que foram historicamente povoadas por grupos originários. 


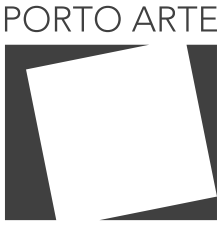

Revista de Artes Visuais

$\vee 25 n .44$

$\mathrm{Jul} / \mathrm{dez} 2020$ e-ISSN: 2179-8001

Portanto, enfatizando a afirmação acima: a palavra tabu é ambivalente em si mesma, ou seja, transporta uma ambivalência em seu conceito original. Além disso, Freud faz referência às palavras primitivas do léxico egípcio, abordadas anteriormente, e insere o tabu em um mesmo escopo de conceitos primariamente ambivalentes.

Entrando ainda mais no duplo sentido do tabu - sagrado e impuro -, Freud utilizou novamente as investigações de Wundt para elucidar um ponto em comum entre esse duplo sentido primordial. Segundo ele, um traço que permanecerá comum ao sagrado e ao impuro é o temor ao contato - medo do toque ou delírio de toque (FREUD, 2012, p. 52). Ou seja, o temor de entrar em contato - contato direto com o corpo ou em linguagem figurada - com aquilo que é sagrado e impuro. Tal constatação nos leva a movimentos conceituais interessantes para nosso estudo sobre o inconsciente. Em seu trabalho, Freud busca formatar uma dimensão teórica e clínica em torno da neurose. No entanto, não ampliaremos essa perspectiva aqui, apenas acompanharemos o percurso freudiano ao tratar da ação de uma proibição sobre nosso aparelho psíquico. Portanto, Freud investiga o patrimônio psíquico herdado pelo tabu e cristalizado na semelhança do temor ao contato com algo que se exprime em nossa vida psíquica a partir da simultaneidade entre desejo e proibição - sendo a proibição uma espécie de contradesejo: "Onde existe uma proibição deve esconder-se um desejo" (FREUD, 2012, p. 115).

Como já abordado no início da nossa investigação, podemos tomar a repressão de um desejo como algo que institui o inconsciente. Assim, conclui Freud, "o fundamento do tabu é uma ação proibida, para a qual há um forte pendor no inconsciente" (FREUD, 2012, p. 61). A atitude ambivalente como um artifício do nosso aparelho psíquico pode ser observada em costumes e cerimônias de povos que detinham o tabu em sua relação com inimigos, soberanos e mortos. Em suma, "a vida emocional dos primitivos possui elevado grau de ambivalência" (FREUD, 2012, p. 67) - desse modo, o amor e o ódio (amódio ${ }^{10}$ ), por exemplo, instauram-se intimamente em um mesmo lugar.

Nas palavras de Freud, o paradigma da ambivalência dos afetos humanos pode ser demonstrado na íntima relação simultânea entre o amor e o ódio na constituição psíquica, em maior ou menor grau, de qualquer pessoa:

A observação clínica nos mostra que o ódio é não somente o inesperado acompanhante regular do amor (ambivalência), não apenas o seu frequente precursor nas relações humanas, mas também que o ódio, em várias circunstâncias, transforma-se em amor, e o amor, em ódio (FREUD, 2011, p. 53).

Segundo ele, a hostilidade oculta por trás do amor, presente no inconsciente, existe em quase todos os casos de intensa ligação afetiva (FREUD, 2012, p. 102). Ou seja, manifesta-se justamente na relação com as pessoas mais amadas, onde menos seria esperada. Portanto, a ocorrência de uma ação de ternura excessiva em uma relação 


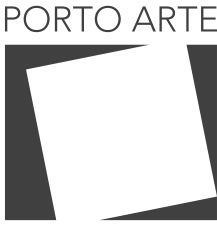

Revista de Artes Visuais

v $25 n \cdot 44$

$\mathrm{Jul} / \mathrm{dez} 2020$ e-ISSN: 2179-8001

afetiva intensa transporta, em casos bastante comuns, uma corrente oposta, inconsciente, de hostilidade (FREUD, 2012, p. 85).

Indo mais fundo, Freud destaca que, na raiz da proibição - que instaura o reprimido no inconsciente -, há frequentemente um desejo de morte em relação à pessoa amada (FREUD, 2012, p. 118). De imediato, essa constatação pode gerar certa resistência em nós. Porém, acompanhando nosso percurso teórico, retomemos algo já levantado: a resistência é justamente um mecanismo de defesa do nosso aparelho psíquico, uma forma da nossa consciência se defender dos desejos mais primitivos e profundos que nos habita.

Perante os pressupostos apresentados, uma afirmação se faz legítima: a ambivalência é um princípio de ação derivada do inconsciente. Como vimos em Freud, as ações do inconsciente localizadas em palavras e afetos nos dão sustentação para tal afirmativa. Além de abrigar um processo psíquico primário, uma realidade própria e uma atemporalidade, o inconsciente não reconhece o que chamamos de contradição: "Tudo leva a crer que existe um certo ponto do espírito de onde a vida e a morte, o real e o imaginário, o passado e o futuro, o comunicável e o incomunicável, o alto e o baixo deixam de ser percebidos como coisas contraditórias (BRETON, 2001, p. 154).

Esse funcionamento não contraditório é o que MD Magno chama de halo bífido do inconsciente. Segundo ele, "os elementos constituintes do Inconsciente são pré-opositivos" (MAGNO, 2010, p. 3), logo, "nosso funcionamento mental - digamos, pré-linguístico - é bífido" (MAGNO, 2015, p. 203). Em outras palavras, o conceito de ambivalência que abordamos em nosso trabalho possui uma fundação anterior à linguagem. Portanto, só podemos analisar a composição do que chamamos aqui de ambivalência se tivermos clareza que sua origem é pré-opositiva, anterior às oposições conscientes, que seu princípio de atuação deriva dos mecanismos inconscientes abordados pela psicanálise freudiana. Sendo mais precisos e delimitando melhor o conceito de acordo com sua etimologia, ambivalência significa ambos valem, ou seja, ambos elementos possuem a mesma força, a mesma potência, a mesma valência.

Antes de prosseguirmos, torna-se necessário aqui fazer uma ressalva: em seu estudo, Freud abordou a origem ambivalente de palavras originárias da língua egípcia e da palavra polinésia tabu. No entanto, saiamos agora do território estrito da língua falada e escrita, e entremos no território próprio das imagens: "uma imagem poética abala toda a atividade linguística. A imagem poética nos coloca diante da origem do ser falante" (BACHELARD, 1984, p. 187). Sendo assim, deixemos as imagens se apresentarem em sua composição expressiva, em sua formação visual própria.

\section{Imagem: pensamentos visíveis}

Após nossa apresentação inicial do conceito de inconsciente nos estudos de Freud e da investigação da ambivalência como um derivado do inconsciente, podemos dar um passo adiante. Esse passo será orientado pela obra plástica de René Magritte. Buscando tornar visível seu pensamento, Magritte trabalhou profundamente a ambivalência em suas pinturas: "Eu faço uso da pintura para tornar os pensamentos visíveis" (MA- 


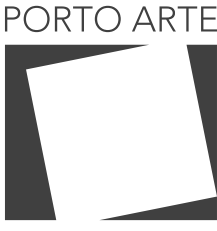

Revista de Artes Visuais

$\vee 25 n .44$

$\mathrm{Jul} / \mathrm{dez} 2020$ e-ISSN: 2179-8001

GRITTE apud PAQUET, 2000). Podemos localizá-lo, historicamente, como integrante do surrealismo ${ }^{11}$, no entanto, não nos deteremos especificamente ao vigor surrealista adotado por Magritte, mas ao quanto seu trabalho nos permite manejar um processo de criação possível referente às excitações intelectuais produzidas pela ambivalência. Para fins didáticos, analisaremos aqui a reversibilidade entre as dimensões do interior e do exterior presentes na obra plástica de Magritte.

Em O Espelho Falso (figura 1), de 1935, Magritte nos apresenta a abertura de um olho. Nesse olho, o contorno da íris ocular forma a imagem do céu. Assim, em um movimento de reversibilidade, vemos o céu (exterior) dentro do olhar (interior). Como nos diz o título da obra, o olho como "espelho da alma" (provérbio) se torna falso. Um interior abriga um exterior e a noção entre sujeito e objeto é emaranhada no fenômeno visual. o que há na imagem é uma ambivalência entre o que observa e o que é observado: "De uma vez por todas, o ser-objeto se coloca diante de mim como o único dotado de sentido" (MERLEAU-PONTY, 2012, p. 55):

\footnotetext{
Quando encontro o mundo atual tal como é, sob minhas mãos, sob meus olhos, contra meu corpo, encontro muito mais do que um objeto: ser de que minha visão faz parte, uma visibilidade mais velha que minhas operações ou atos. Isso, porém, não quer dizer que haja, de mim para ele, fusão, coincidência: ao contrário, isso se faz porque uma espécie de deiscência fende meu corpo em dois e, entre ele olhando e ele olhado, ele tocando e ele tocado, há recobrimento e imbricação, sendo, pois, mister dizer que as coisas passam por dentro de nós, assim como nós por dentro das coisas (MERLEAU-PONTY, 2012, p. 121).
}

Se as coisas passam por dentro de nós e nós por dentro das coisas, ou seja, se o exterior atravessa o interior e o interior atravessa o exterior, obtemos uma ambivalência viva instaurada em todo fenômeno de observação. Em outras palavras, em todo e qualquer ato de observação, há reversibilidade e consonância: "é por sua 'imensidão' que os dois espaços: o espaço da intimidade e o espaço do mundo se tornam consoantes" (BACHELARD, 1984, p. 329). No quadro de Magritte, a imensidão se encontra onde a profundeza do olhar toca e abriga a vastidão do céu.

Em A Condição Humana (figura 2), também de 1935, ao invés dos elementos olho e céu, presentes em 0 Espelho Falso (figura 1), temos os elementos quadro (tela sustentada pelo cavalete) e oceano. Podemos verificar que o pensamento visível trabalhado por Magritte é o mesmo. As bordas da tela sustentada pelo cavalete formam um enquadramento, um campo de visão, ou seja, uma dimensão do olhar. O oceano, assim como o céu, é um horizonte azul de vastidão. Uma referência deixada por Magritte para

11- Surrealismo, segundo a origem da palavra, significa "super-real", "acima do real", "para além do real". O termo foi criado, em 1917, por Guillaume Apollinaire (1880-1918) e tornado movimento por André Breton (1896-1966) em três manifestos: o Manifesto do Surrealismo, de 1924; o Segundo Manifesto do Surrealismo, de 1930; e o Prolegômenos a um Terceiro Manifesto do Surrealismo ou Não, de 1942. 


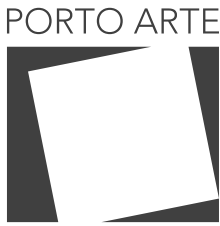

Revista de Artes Visuais

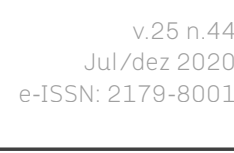

Figura 1: René Magritte O Espelho Falso (Le Faux Miroir), 1935 Óleo sobre tela, $19 \times 27 \mathrm{~cm}$ Coleção particula Fonte: PAQUET, 2000, p. 11

que possamos fazer o vínculo entre ambas as obras é a esfera escura presente no canto inferior esquerdo da porta (figura 2). Assim como o contorno posterior da porta (figura 2) nos remete imediatamente ao contorno da íris ocular (figura 1), a esfera escura (figura 2) nos remete diretamente à pupila do olho (figura 1).

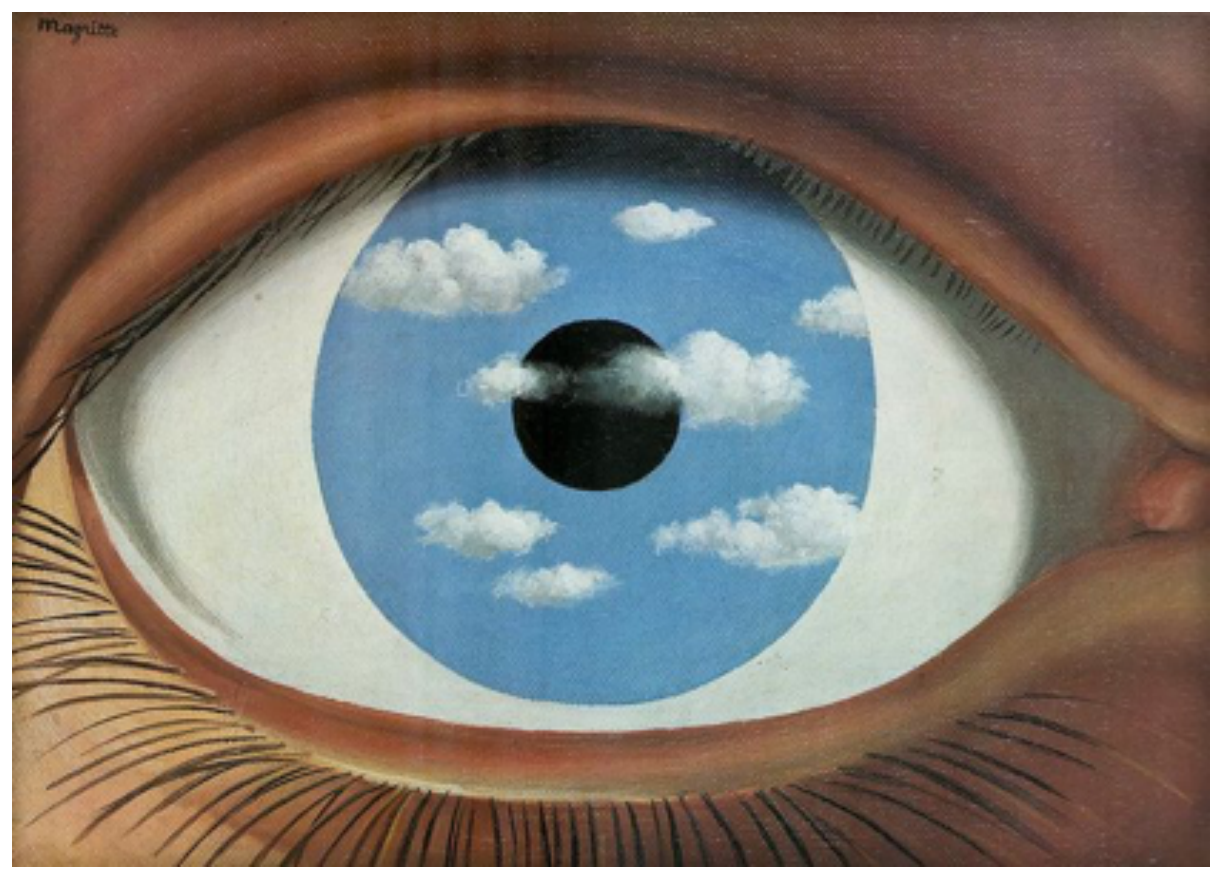

Novamente, Magritte nos apresenta a ambivalência entre interior e exterior. 0 interior da tela sustentada pelo cavalete (figura 2) possui a pintura da paisagem oceânica. Essa pintura nos coloca um enigma: é pintada de acordo com o campo de visão diagonal que um hipotético pintor teria através do contorno da porta ou é a continuidade do oceano que penetrou o interior da tela? Não é o caso aqui de resolvermos o enigma, mas de admiti-lo em sua potencialidade. Não há um pintor pintado dentro da obra, o único pintor que podemos considerar, portanto, é o próprio Magritte. Toda a obra é composta por um mesmo elemento: a pintura. 0 oceano é pintado assim como a tela sustentada pelo cavalete, assim como a pintura no interior da tela sustentado pelo cavalete. Desse modo, podemos analisar camadas diversas de ambivalência. Em uma primeira camada, há a ambivalência entre o interior e o exterior da obra. Magritte pinta uma tela dentro da tela, formando assim uma tela interior e uma tela exterior em uma mesma obra. Em uma segunda camada, ao pintar a tela dentro da tela, cria um interior-exterior no interior da obra. Quando o interior da tela sustentada pelo cavalete é criado no interior da obra, temos a criação simultânea de um exterior no interior da obra. 0 oceano, a porta e a esfera fazem parte dessa dimensão exterior no interior da obra. Portanto, quando o oceano (exterior do interior) penetra o interior da tela sustentada pelo cavalete (interior do interior), temos a formação da ambivalência de uma ambivalência. 


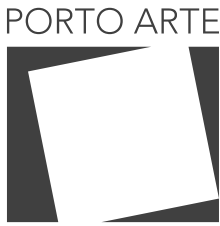

Revista de Artes Visuais

v.25 n.44 $\mathrm{Jul} / \mathrm{dez} 2020$ e-ISSN: 2179-8001
Figura 2: René Magritte, A Condição Humana (La Condition Humaine), 1935 Óleo sobre tela, $100 \times 81 \mathrm{~cm}$ Genebra, Coleção Simon Spierer Fonte: PAQUET, 2000, p. 66
Retomando o vínculo entre as obras apresentadas (figuras 1 e 2), o interior do olho que abriga a vastidão do céu (figura 1) é pensado, analogamente, como o interior da tela que abriga a vastidão do oceano (figura 2). Porém, em A Condição Humana, Magritte amplia seu pensamento. Não só cria um interior (tela sustentada pelo cavalete) que transporta um exterior (oceano) - como em O Espelho Falso -, mas também um exterior (a própria obra) que transporta um interior (tela sustentada pelo cavalete). Magritte cria uma pintura dentro da pintura, trabalhando os limites do próprio meio pictórico e destituindo visualmente as bordas entre o que é interior e o que é exterior em uma pintura.

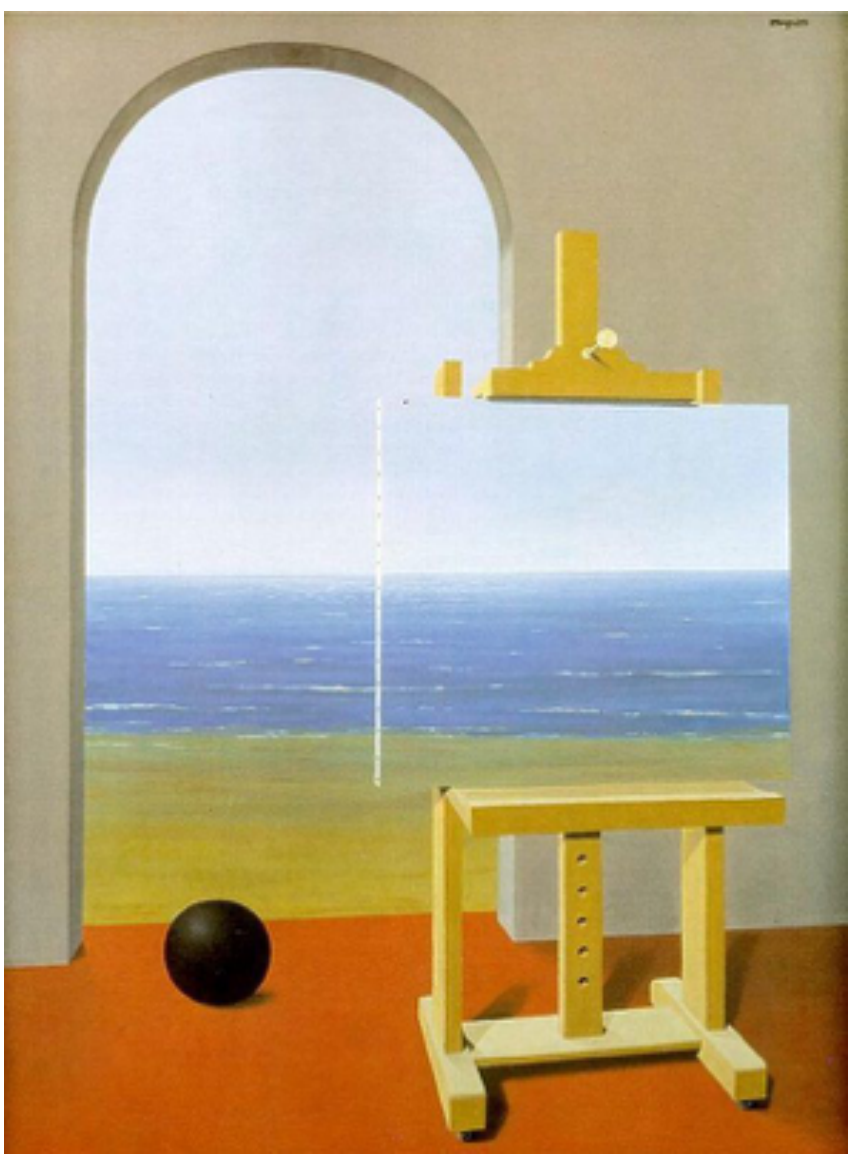

Em Elogio da Dialética (figura 3), de 1936, a reversibilidade entre o espaço de dentro e o espaço de fora é novamente abordado de modo ambivalente por Magritte. Uma janela aberta nos direciona ao interior de uma casa. Porém, estando lá, a imagem não nos mostra o interior do cômodo, mas o exterior de outra casa (definida pelo diferente design presente na janela e no telhado). 0 quadro compõe uma ambivalência na qual ambos os elementos, interior e exterior, dialeticamente, penetram-se. Como descrito no título, há um pensamento dialético fundamental, compondo, de fato, um elogio: sempre quando entramos também saímos, o fora está no dentro e o dentro está no fora. 0 pen- 


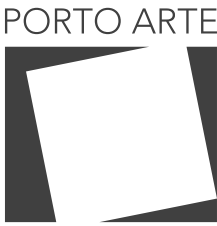

Revista de Artes Visuais

v. 25 n. 44 $\mathrm{Jul} / \mathrm{dez} 2020$ e-ISSN: 2179-8001
Figura 3: René Magritte Elogio da Dialética (Eloge de la Dialectique), 1936 Aquarela. Coleção particular Fonte: PAQUET, 2000, p. 20 samento dialético é o que "admite que cada termo só é ele mesmo voltando-se para o termo oposto, torna-se o que é pelo movimento, sendo a mesma coisa para cada um passar para o outro ou vir a ser si mesmo, sair de si ou entrar em si" (MERLEAU-PONTY, 2012, p. 92). Portanto, de acordo com a dialética apresentada, o interior só existe por meio do exterior e o exterior só existe por meio do interior. O movimento dialético se transforma, assim, "na identidade pura dos opostos, em ambivalência" (MERLEAU-PONTY, 2012, p. 94).

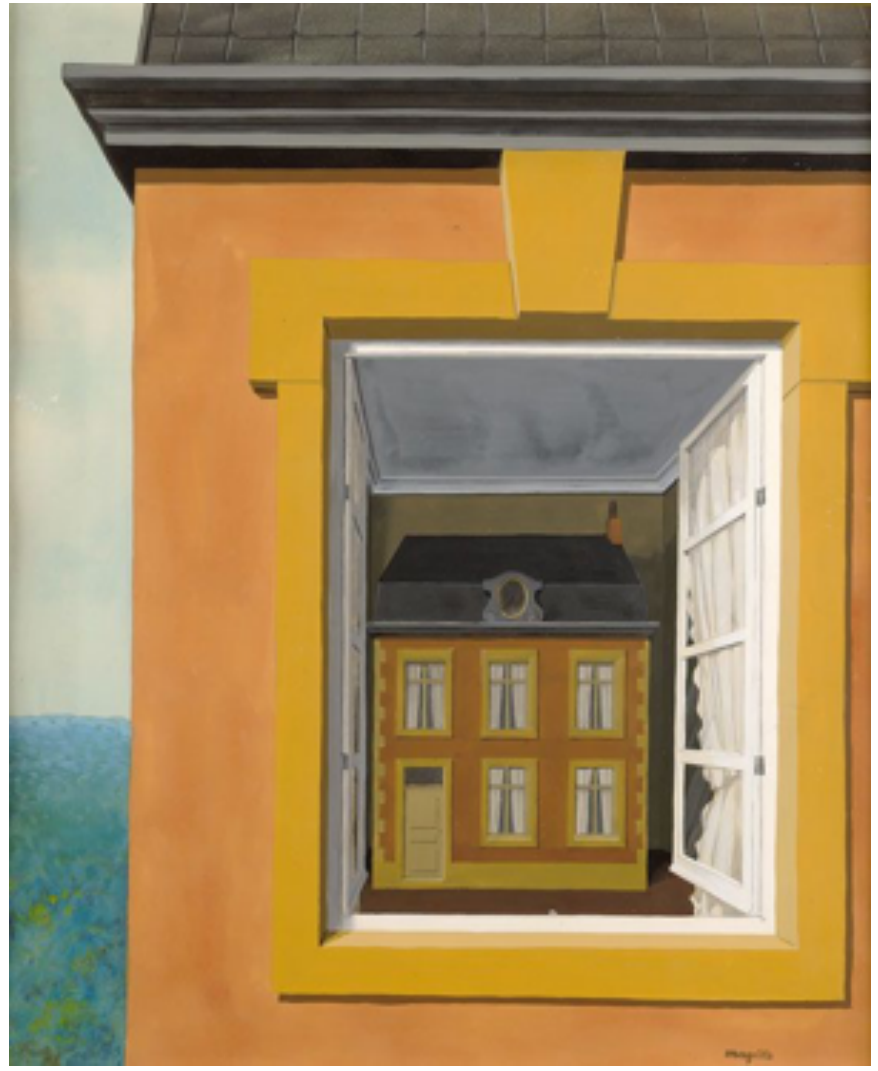

Em Perspicácia - Autorretrato (figura 4), também de 1936, Magritte nos apresenta novamente um quadro pintado dentro do quadro. Diferentemente de A Condição Humana (figura 2), o pintor é revelado, ele (o próprio Magritte) está pintando no interior da sua pintura. Assim como ocorre na figura 2, temos duas camadas de ambivalência. Para além da ambivalência criada a partir do quadro exterior e do quadro interior, do pintor interior e do pintor exterior, podemos observar que a obra nos direciona para outra dimensão interior-exterior em sua composição. Há um possível arranjo entre o que está fora e o que potencialmente pode estar dentro, um arranjo entre o presente e o futuro, uma vidência entre a atualidade e a virtualidade: "Olho o ovo com um só olhar. Imediatamente percebo que não se pode estar vendo um ovo. Ver um ovo nunca se mantém no presente" (LISPECTOR, 2016, p. 303). Na obra, Magritte se pinta observando um ovo que está sobre uma mesa. Porém, 


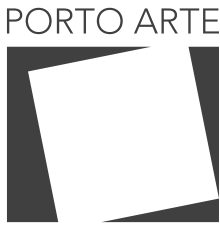

Revista de Artes Visuais

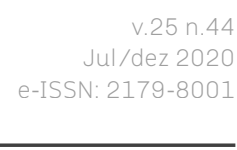

Figura 4: René Magritte Perspicácia - Autorretrato (La Clairvoyance (Autoportrait)), 1936 Óleo sobre tela, $54,5 \times 65,5 \mathrm{~cm}$ Bruxelas, Galerie Isy Brachot Fonte: PAQUET, 2000, p. 24 no quadro dentro do quadro, há a pintura de um pássaro. Portanto, no interior da obra, o pintor pintado olha um ovo e pinta um pássaro: um ovo (atual) que transporta, em seu interior, a vida potencial de um pássaro (virtual). 0 ovo é interior à tela externa e exterior à tela interna. 0 pássaro é interior à tela interna, interior ao interior da tela externa e virtualmente exterior ao ovo. 0 pássaro existe na imaginação criadora do pintor interior. 0 pássaro, o ovo e o pintor interior existem na imaginação criadora do pintor exterior.

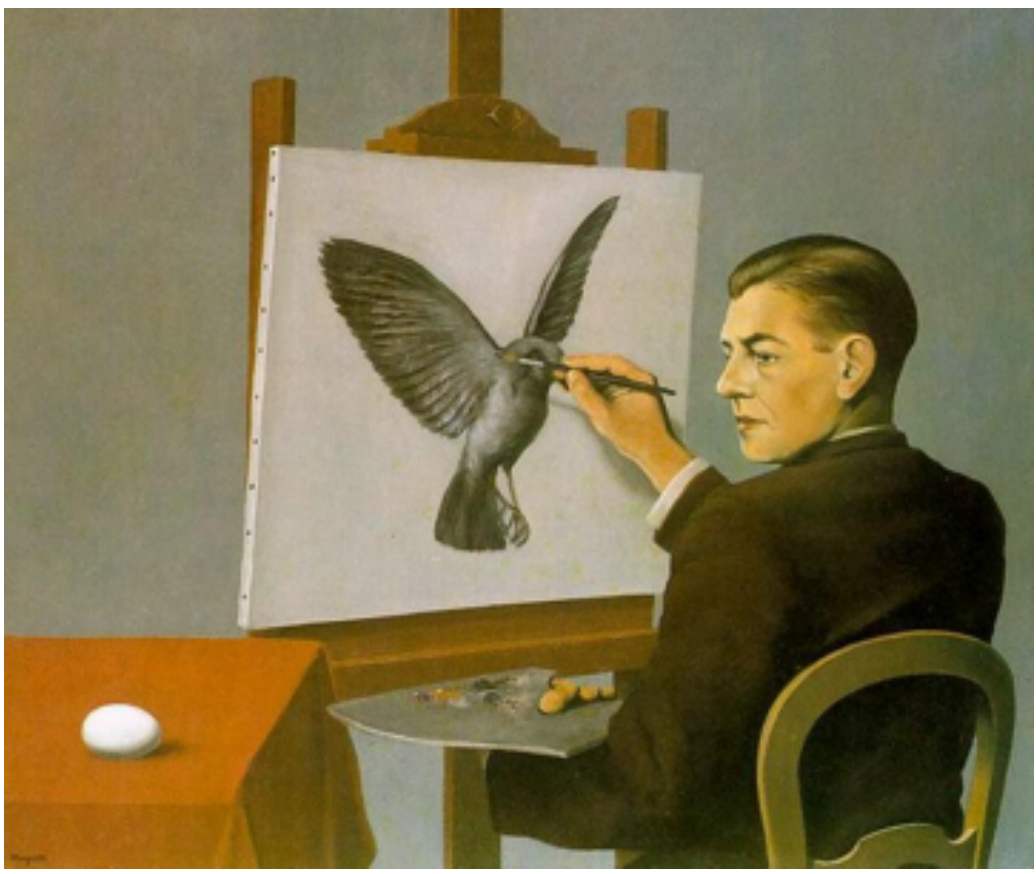

Desse modo, Magritte se cria criando, processando ambivalências referentes ao próprio processo de criação. A criação é um processo que incorpora princípios de reversibilidade e dialética, de internalização e externalização, de fechamento e abertura: "É um processo contínuo que se regenera por si mesmo e onde o ampliar e o delimitar representam aspectos concomitantes, aspectos que se encontram em oposição e tensa unificação. A cada etapa, o delimitar participa do ampliar" (OSTROWER, 2014, p. 26). A criação se elabora, portanto, por meio de um contínuo delimitar e ampliar, em oposição e unificação (ambivalência). Ou seja, nos exemplos que usamos referentes à obra plástica de Magritte, o interior e o exterior se transitam e se transam em ambivalência, delimitando e ampliando dimensões de sentido.

É esse laboratório mental de criação que buscamos esboçar no processo do nosso estudo: delimitar um arcabouço teórico e pictórico para, analogamente, ampliá-lo em uma ferramenta conceitual. Em outras palavras, delimitar as palavras originárias e os pensamentos visíveis para ampliá-los em uma poética visual da ambivalência. Em seguida, desejamos delimitar essa poética no intuito de expandi-la, alargá-la, abri-la para futuras investigações. 


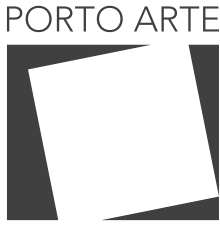

Revista de Artes Visuais

v $25 n .44$

Jul/dez 2020 e-ISSN: 2179-8001

\section{Criação: uma poética visual da ambivalência}

Tomaremos a palavra poética no mesmo sentido que Aristóteles (384 a. EC - 322 a.EC) a utilizou para discutir a artesania da tragédia: como modo de composição (ARISTÓTELES, 2017). Entendendo a palavra poética segundo sua origem: "como nome de tudo que se relaciona com a criação ou com a composição de obras em que a linguagem é ao mesmo tempo substância e meio" (VALÉRY, 2018, p. 13). Ou seja, poética (poiesis, derivado do grego antigo) significa compor, fabricar, produzir, fazer, criar: "Há, nessa palavra, uma densidade metafísica e cosmológica que precisamos ter em vista. Significa um produzir que dá forma, um fabricar que engendra, uma criação que organiza, ordena e instaura uma realidade nova" (NUNES, 2016, pp. 21-22).

Retomemos aqui a edificação do nosso estudo no intuito de articularmos as concepções apresentadas nos tópicos anteriores e elaborarmos uma direção possível para desenvolvermos o esboço de uma poética: "Poema como base inconcreta de criação" (HELDER, 2006, p. 110). Uma poética que tenha a ambivalência como base inconcreta de criação.

No primeiro tópico do nosso trabalho, consideramos o estudo de Freud em torno do conceito de inconsciente. Freud nos apresenta a pedra angular da psicanálise: o recalque. O recalque, enquanto mecanismo de defesa, instaura o inconsciente - que somente pode ser verificado por meio de derivações. 0 inconsciente freudiano possui quatro características próprias: a ausência de contradição, o processo psíquico primário, a substituição da realidade externa pela realidade psíquica e a atemporalidade. A investigação de palavras primitivas da antiga língua egípcia e da palavra polinésia tabu nos ofereceu um arcabouço conceitual para aprofundarmos a primeira característica descrita por Freud: a ausência de contradição. Verificamos que a ausência de contradição pode ser observada nos conceitos originários que tomamos como exemplo. Essa ausência de contradição verificada trouxe à tona a ambivalência - a ambivalência como derivação do inconsciente.

No segundo tópico, para tomarmos a ambivalência como substância e meio de criação, investigamos a obra plástica de Magritte. Freud e Magritte possuem um lugar de vinculação: o surrealismo. 0 aparelho de atuação aprimorado por Breton em torno da vanguarda surrealista tem, nos estudos de Freud, uma base teórica primordial. Magritte, como integrante do movimento, influenciou-se dessa base teórica - o que podemos constatar na atmosfera onírica e conceitual das suas obras.

Quando analisamos a reversibilidade entre a dimensão interior e a dimensão exterior em determinadas obras de Magritte, detectamos que tais dimensões só existem em concomitância. Ou seja, o interior só existe porque há um exterior e o exterior só existe porque há um interior. Essa constatação se aproxima do que Abel verificou nas palavras primitivas da língua egípcia: "todo conceito é irmão gêmeo de seu oposto", ou seja, todos os conceitos opostos nascem juntos. Interior e exterior são manejados pelo pensamento visível de Magritte como conceitos originalmente pré-opositivos. Magritte reverte as referências habituais e indiferencia as dimensões em direção à sua fonte bífida. Todo o interior carrega um exterior e todo exterior carrega um interior: o olho comporta o céu (figura 1), o quadro comporta o oceano (figura 2), a casa comporta a 


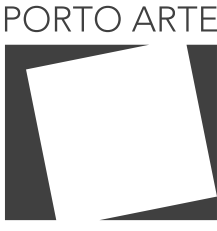

Revista de Artes Visuais

v $25 n .44$

Jul/dez 2020 e-ISSN: 2179-8001

casa (figura 3), a pintura comporta o pintor e o ovo comporta o pássaro (figura 4). Assim como cada noção carrega sua noção oposta na dimensão conceitual do tabu: o impuro comporta o sagrado e a proibição comporta o desejo.

A impureza sagrada e o desejo proibido contido na palavra tabu são, de acordo com Freud, modos primordiais de ambivalência. Se podemos constatar, em uma mesma palavra, as noções de sagrado (pureza) e impuro - emaranhadas pelo temor ao contato - e as noções de desejo e proibição (contradesejo), temos um elemento instaurador em um mesmo sentido que tomamos aqui enquanto poética. Pois podemos considerar a invenção da palavra tabu, pelos povos originários, como um ato poético. Um ato poético que tem a ambivalência como válvula propulsora. É justamente o processo do ato poético, propulsionado pela ambivalência, que buscamos esboçar em nosso trabalho. Ou seja, o processo pelo qual a ambivalência toma forma. No caso do tabu e das palavras da antiga língua egípcia, a ambivalência toma a forma de conceitos bífidos. No caso dos pensamentos visíveis de Magritte, a ambivalência toma a forma de uma visualidade bífida. Consideremos, portanto, as obras plásticas de Magritte como exemplos basais na direção do esboço do que chamamos aqui de poética visual da ambivalência.

Podemos localizar os trabalhos de Freud e Magritte, apresentados no decorrer do nosso estudo, como trabalhos inseridos no contexto da primeira metade do século $X X$ Ambos foram pensadores relevantes para o aprimoramento da arte moderna através, principalmente, da vanguarda surrealista. Além disso, são pensadores impactantes no amplo campo que concebemos hoje como arte contemporânea.

Dando nova dignidade ao conceito de inconsciente, Freud disponibilizou um instrumento poderoso para poetas e artistas. Um instrumento dotado da sua própria lógica primordial - originária em relação a logos da filosofia clássica que se constrói demasiadamente vinculada aos mecanismos conscientes. Magritte utilizou esse fugidio instrumento com eloquência, deixando-se pensar pelo instrumento, deixando-se penetrar pelos princípios do instrumento. Magritte pensou visualmente o pensamento. Não só o pensamento racional (atrelado à logos clássica), mas o pensamento poético em toda sua dimensão inconsciente fundamental. As obras plásticas de Magritte se inserem no ponto onde ambivalência e imagem se emaranham em um laboratório mental de criação, ou seja, em uma poética.

Diante disso, não buscamos aqui delimitar a poética, mas uma poética visual da ambivalência. Ou seja, um - entre muitos - caminhos possíveis de pensarmos modos de composição visual a partir das excitações intelectuais provocadas pela ambivalência. Portanto, os aperfeiçoamentos posteriores referentes ao que chamamos de poética visual da ambivalência requerem acompanhamentos contínuos e aprofundados dos processos de formação, composição e criação de derivações ambivalentes. É uma poética lavrada em um campo transdisciplinar - nos transes e nas transas das disciplinas. Sendo assim, o que pretendemos nesse breve trabalho é, de fato, aprimorar um rascunho, sofisticar um inacabamento premeditado. Tivemos o objetivo, no decorrer da investigação, de darmos uma borda inicial possível ao que chamamos de poética visual da ambivalência para que possamos agora, nessa conclusão, abri-la para diálogos e extensões. Ou seja, para que possamos, ambivalentemente, concluir introduzindo. 


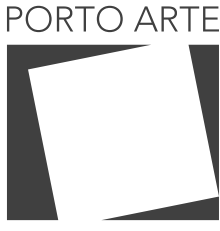

Revista de Artes Visuais

$\vee 25 n .44$ $\mathrm{Jul} / \mathrm{dez} 2020$ e-ISSN: 2179-8001

\section{Referências bibliográficas}

APOLLINAIRE, G. As mamas de Tirésias - drama surrealista em dois actos e um prólogo. Tradução de Aníbal Fernandes. Lisboa: Sistema Solar, 2012.

ARISTÓTELES. Poética. Tradução de Paulo Pinheiro. São Paulo: Editora 34, 2017.

BACHELARD, G. A poética do espaço. In: Bachelard (Os Pensadores) - Seleção de textos de José Américo Pessanha. Tradução de Joaquim José Moura Ramos. São Paulo: Abril Cultural, 1984.

BRETON, A. Manifestos do surrealismo. Tradução de Sergio Pachá. Rio de Janeiro: Nau, 2001.

CHAUI-BERLINCK, L. O inconsciente. São Paulo: Editora WMF Martins Fontes, 2014.

FREUD, S. Observações psicanalíticas sobre um caso de paranoia relatado em autobiografia ("O caso Schreber"), Artigo sobre técnica e outros textos (1911-1913). Obras completas - Volume 10. Tradução de Paulo César de Souza. São Paulo: Companhia das Letras, 2010a.

FREUD, S. Introdução ao narcisismo, Ensaios de metapsicologia e outros textos (19141916). Obras completas - Volume 12. Tradução de Paulo César de Souza. São Paulo: Companhia das Letras, 2010b.

FREUD, S. O Eu e o Id, "Autobiografia" e outros textos (1923-1925). Obras completas - Volume 16. Tradução de Paulo César de Souza. São Paulo: Companhia das Letras, 2011.

FREUD, S.. Totem e tabu, Contribuição à história do movimento psicanalítico e outros textos (1912-1914). Obras completas - Volume 11. Tradução de Paulo César de Souza. São Paulo: Companhia das Letras, 2012.

FREUD, S. Observações sobre um caso de neurose obsessiva ("O homem dos ratos"), Uma recordação de infância de Leonardo da Vinci e outros textos (1909-1910). Obras completas - Volume 9. Tradução de Paulo César de Souza. São Paulo: Companhia das Letras, 2013.

FREUD, S. A interpretação dos sonhos. Tradução do alemão de Renato Zwick. Porto Alegre: L\&PM, 2016.

HELDER, H. Ou o poema contínuo. São Paulo: A Girafa, 2006.

LACAN, J. O seminário, livro 20 - Mais, ainda. Tradução de MD Magno. Rio de Janeiro: Zahar, 1985.

LISPECTOR, C. Todos os contos. Rio de Janeiro: Rocco, 2016.

MAGNO, MD. "O halo bífido do inconsciente". In: TRANZ: revista de estudos transitivos do contemporâneo. № 5, 2010.

FREUD, S. ZIG/JAC: MAG - Razão de um percurso. Rio de Janeiro: Novamente, 2015.

MERLEAU-PONTY, M. O Visível e o Invisível. Tradução de José Artur Gianotti e Armando Mora d'Oliveira. São Paulo: Perspectiva, 2012.

NUNES, B. Introdução à filosofia da arte. São Paulo: Edições Loyola, 2016.

OSTROWER, F. Criatividade e processos de criação. Petrópolis: Vozes, 2014.

PAQUET, M. Magritte. Tradução de Lucília Filipe. Köln: Taschen, 2000.

VALÉRY, P. Lições de poética. Tradução de Pedro Sette-Câmara. Belo Horizonte: Editora Âyiné, 2018. 


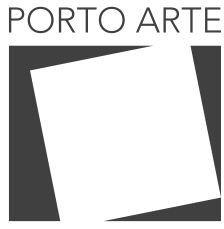

Revista de Artes Visuais

V.25 n. 44

Jul/dez 2020

e-ISSN: 2179-8001

\section{Diego Rezende}

Possui doutorado em Artes Visuais pela Universidade Federal do Rio de Janeiro. Atua como pesquisador no campo transdisciplinar da poética. Trabalha em Belo Horizonte.

Texto submetido em: 14/08/2020

Texto aceito em: 14/10/2020

Texto publicado em: 20/12/2020 